\title{
Rancang Bangun Kursi Roda Elektrik untuk Disabilitas Berbasis Microkontroler Atmega 328
}

${ }^{1}$ Badrul Wajdi, ${ }^{2}$ Sapiruddin, ${ }^{3}$ Tsamarul Hizbi, ${ }^{4}$ Sudaisi Hafizin

${ }^{1,2,3,4}$ Prodi Pendidikan Fisika, FMIPA, Universitas Hamzanwadi, Jln. TGKH. Muhammad Zainuddin Abdul Madjid No. 132 Pancor Selong, Lombok Timur, NTB, 83611

Email Korespondensi: syahrial_ayub@unram.ac.id

\begin{tabular}{|c|c|}
\hline Article Info & bstract \\
\hline $\begin{array}{l}\text { Article History } \\
\text { Received: } 22 \text { Dec } 2021 \\
\text { Revised: } 26 \text { Dec } 2021 \\
\text { Published: } 30 \text { Dec } 2021\end{array}$ & \multirow{2}{*}{$\begin{array}{l}\text { The purpose of making this tool is to design and manufacture an electric } \\
\text { wheelchair for disabilities based on the ATMega328 microcontroller. This tool } \\
\text { is expected to make it easier for users who use wheelchairs to be able to use } \\
\text { them independently. The design of an electric wheelchair for disabilities based } \\
\text { on the ATmega328 microcontroller consists of several stages starting from the } \\
\text { needs identification stage, needs analysis, circuit design, tool modification, } \\
\text { program flowchart, tool evaluation, and data collection. The main components } \\
\text { used as the main control are Arduino UNO (ATMega 328), joystick as control } \\
\text { medium, DC driver as rotation regulator, and DC motor as wheelchair } \\
\text { propulsion. Based on the test results, the results of the control experiment using } \\
\text { a joystick and a microcontroller produce the wheelchair movement output } \\
\text { according to the instructions that have been set as input. The wheelchair can } \\
\text { move with instructions, Forward, Backward, Left, Right, and Stop. The } \\
\text { wheelchair can carry a maximum user load of } 25 \text { kg, plus a battery load and a } \\
\text { DC motor of } 25 \text { kg, a total load that can be carried is } 50 \text { kg. The results of } \\
\text { testing the performance of the system can work in accordance with its functions } \\
\text { and objectives. }\end{array}$} \\
\hline $\begin{array}{l}\text { Keywords } \\
\text { Wheelchair; electric; } \\
\text { disability; ATMega328 } \\
\text { microcontroller }\end{array}$ & \\
\hline Informasi Artikel & Abstrak \\
\hline $\begin{array}{l}\text { Sejarah Artikel } \\
\text { Diterima: } 22 \text { Des } 2021 \\
\text { Direvisi: 26 Des } 2021 \\
\text { Dipublikasi: } 30 \text { Des } 2021\end{array}$ & \multirow{2}{*}{$\begin{array}{l}\text { Tujuan pembuatan alat ini adalah untuk menghasilkan rancang bangun sebuah } \\
\text { alat bantu kursi roda elektrik untuk disabilitas berbasis mikrokontroler } \\
\text { ATmega328. Alat ini diharapkan dapat mempermudah pengguna yang } \\
\text { menggunakan kursi roda agar dapat menggunakanya secara mandiri. } \\
\text { Perancangan kursi roda elektrik untuk disabilitas berbasis mikrokontroler } \\
\text { ATmega328 terdiri dari beberapa tahap dimulai dari tahap identifikasi } \\
\text { kebutuhan, analisis kebutuhan, perancangan rangkaian, memodifikasi alat, } \\
\text { flowchart program, evaluasi alat, dan pengambilan data. Komponen utama } \\
\text { yang digunakan sebagai kontrol utama adalah Arduino uno (ATmega 328), } \\
\text { joystick sebagai media kendali, driver DC sebagai pengatur putaran. dan motor } \\
\text { DC sebagai penggerak kursi roda. Telah dihasilkan rancang bangun kursi roda } \\
\text { elektrik untuk disabilitas berbasisi mikrokontroler ATmega328 menggunakan } \\
\text { control joystick sebagai pengendali dengan instruksi yang telah diset sebagai } \\
\text { masukan. Kursi roda dapat bergerak dengan instruksi, Maju, Mundur, Kiri, } \\
\text { Kanan, dan Stop. Kursi roda hanya dapat membawa beban maksimal } \\
\text { pengguna sebesar } 25 \mathrm{~kg} \text {, ditambah beban baterai dan motor DC } 25 \mathrm{~kg} \text {, total } \\
\text { keseluruhan beban yang dapat dibawa sebesar } 50 \mathrm{~kg} \text {. }\end{array}$} \\
\hline $\begin{array}{l}\text { Kata kunci } \\
\text { kursi roda; elektrik, } \\
\text { disabilitas; mikrokontroler } \\
\text { ATmega328. }\end{array}$ & \\
\hline
\end{tabular}

Sitasi: Wajdi, B., Sapiruddin, S., Hizbi, T., \& Hafizin, S. (2021), Rancang Bangun Kursi Roda Elektrik untuk Disabilitas Berbasis Microkontroler Atmega 328, Kappa Journal. 5(2), 269-276.

\section{PENDAHULUAN}

Perkembangan teknologi yang semakin canggih di berbagai bidang dapat membantu manusia melakukan aktivitas walaupun dengan keterbatasan, dengan berkembangnya teknologi, banyak inovasi yang dapat diaplikasikan untuk mengembangkan kemampuan diri 
salah satu contohnya adalah merancang kursi roda konvensional menjadi otomatis. Bagi penderita kelumpuhan seperti penderita sakit saraf, penderita lumpuh pada kaki untuk dapat menggerakan kursi roda, setidaknya diperlukan satu orang untuk membantu mendorong kursi roda. Jika tidak ada orang yang mendorong kursi roda tersebut, maka pengguna kursi roda harus menggunakan tenaganya untuk menggerakan kursi roda dengan menggunakan tangan.

Pada sebuah berita yang dimuat pada koran Tempo tahun 2017 menyebutkan sebanyak 80 persen dari pengguna kursi roda di daerah Lombok Tengah adalah penduduk yang kurang mampu (Lombok Pos, 2017). Penduduk yang kurang mampu mayoritas menggunakan kursi roda manual itu pun masih tergolong mahal, dengan harganya yang berkisar dari Rp 1.000.000, sampai dengan Rp 3.000.000(Cakra Negara Elektronik, 2021) sedangkan kursi roda elektrik dengan tenaga baterai dan dikontrol dengan menggunakan joystick, per unit kursi roda seharga Rp 19.500.000 (Careindo, 2021). Meskipun kursi roda elektrik telah banyak diperjual belikan akan tetapi dengan harga tersebut membuat pengguna kursi roda elektrik masih jarang karena harga yang mahal tidak memungkinkan dimiliki oleh pengguna dengan keterbatasan ekonomi.

Pada penelitian sebelumnya, banyak yang merubah kursi roda manual menjadi kursi roda elektrik seperti yang pernah dilakukan oleh Budiman Setyo Utomo (2018) pada penelitian tugas akhirnya dengan menambahkan fitur kontrol sistem. Ada juga penelitian yang pernah dilakukan oleh Pebriono Aji Prasetyo (2019) yaitu menambahkan sensor jarak sebagai pengaman dalam objek dengan memanfaatkan arduino ATmega2560. Namun pada penelitian-penelitian tersebut memerlukan dana yang besar karena suku cadang yang masih tergolong sangat langka dan mahal dapat jadi kendala para penderita disabilitas untuk memiliki kursi roda elektrik seperti yang dirancang oleh peneliti-peneliti di atas.

Berdasarkan permasalahan diatas, penulis bermaksud membuat alat bantu berupa kursi roda elektrik untuk disabilitas berbasis mikrokontroler ATmega328. Teknologi kursi roda elektrik berbasis arduino ATmega328 merupakan sebuah terobosan teknologi yang saat ini banyak diaplikasikan dalam peralatan bantu. Kursi roda ini dirancang dengan peralatan yang sangat sederhana bahan-bahan yang murah, dengan suku cadang yang mudah menjadi daya tarik penulis untuk melakukan penelitian ini, akan tetapi bisa memberikan fungsi seperti halnya kursi roda pada umumnya. Teknologi kursi roda elektrik berbasis Arduino ATmega328 ini diharapkan dapat memudahkan para penyandang disabilitas untuk bisa menggunakan kursi roda elektrik dalam aktifitas sehari-harinya tanpa banyak membebankan orang lain dengan harga yang sangat ekonomis

\section{METODE}

Jenis penelitian yang digunakan adalah penelitian terapan yaitu merancang bangun alat bantu berupa kursi roda elektrik untuk disabilitas berbasis mikrokontroler ATmega328. Pada penelitian ini dilakukan penngujian setiap bagian dari masing-masing alat. Tujuan dari pengujian ini adalah untuk mengetahui setiap bagian dari perangkat telah bekerja sessuai dengan fungsinya. Dalam melakukan penelitian ini digunakan alat sebagai berikut:

Tabel 1. Alat

\begin{tabular}{ccc}
\hline No & Alat & Bahan \\
\hline 1 & Solder & Arduino UNO \\
\hline 2 & Komputer & Driver Motor BTS7960 \\
\hline
\end{tabular}




\begin{tabular}{lcl}
\hline 3 & Kabel Port USB & Joystik \\
\hline 4 & Konci & Kabel \\
\hline 5 & Obeng & Baterai \\
\hline 6 & Tang & Motor DC \\
\hline 7 & Mesin las & Korsi \\
\hline 8 & - & Mur dan baut \\
\hline 9 & - & Roda dan Gear set \\
\hline
\end{tabular}

\section{HASIL DAN PEMBAHASAN}

Pengujian alat ini memiliki tujuan untuk menentukan kinerja dari alat yang sudah dirancang serta hubungan antara perangkat keras dengan perangkat lunak sebagai program aplikasi system. Dengan pengujian ini dapat diketahui apakah alat dan aplikasi yang telah dirancang dapat merespon perintah yang akan dibutuhkan oleh pengguna untuk menjalankan kursi roda.

1. Pengujian Catu Daya Baterai aki $12 \mathrm{~V}$

Pengujian dilakukan untuk mengetahui tegangan maksimal sampai minimal keluaran baterai yang digunakan dan pengukuran waktu lamanya baterai dapat bertahan. Tabel di bawah berikut merupakan table hasil pengujian baterai.

Tabel 2. Pengujian Daya Tahan Baterai

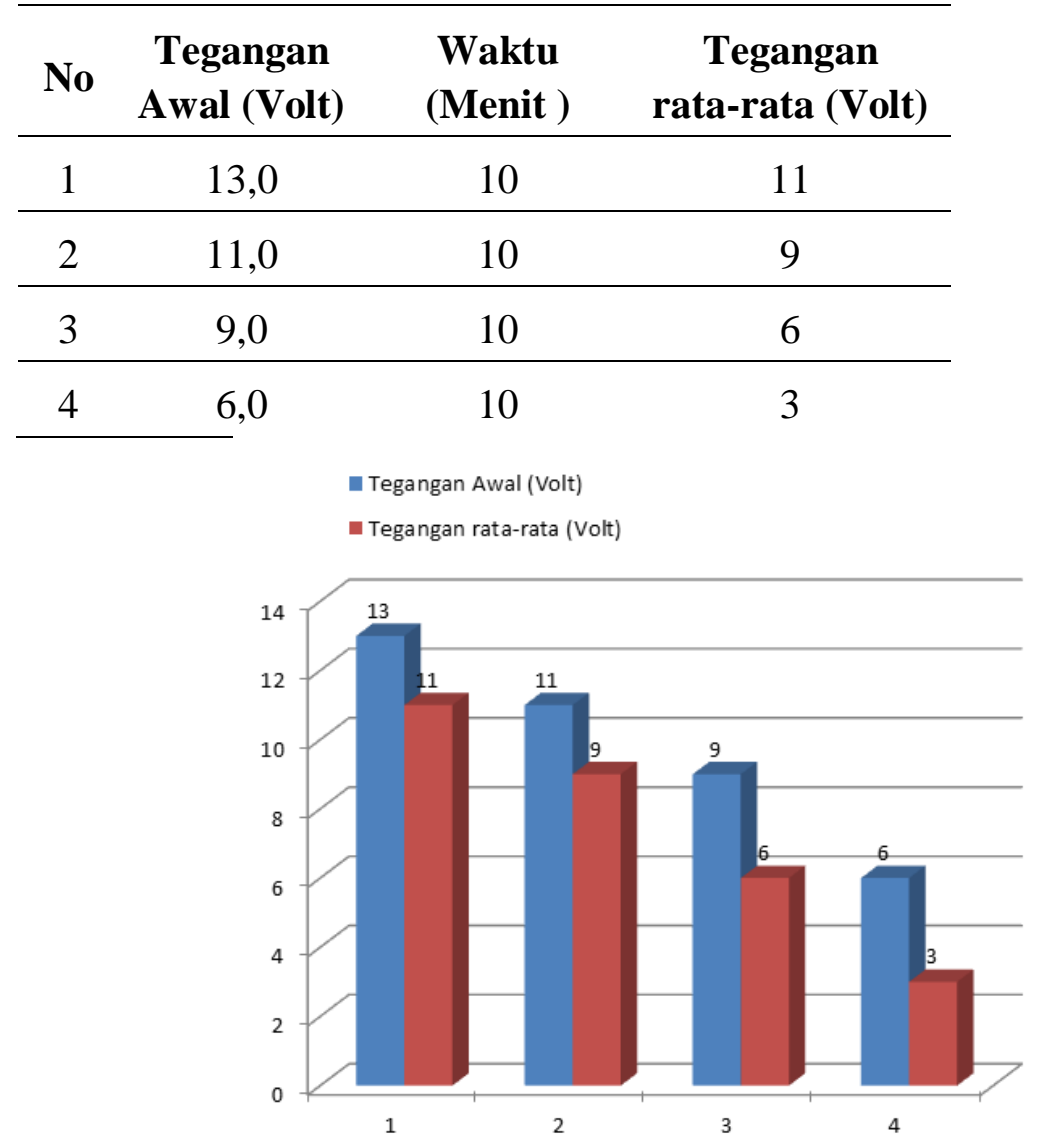

Gambar 1. Pengujian Daya Tahan Baterai 
2. Pengujian Motor DC

Pengujian motor DC ini di lakukan untuk mengetahui kondisi kerja berupa putaran dari motor DC apakah dapat bekerja dengan baik atau tidak. Tabel 3 dan gambar 2 dan gambar 3 merupakan hasil pengujian motor DC.

Tabel 3. Pengujian pada Motor DC

\begin{tabular}{cccccc}
\hline No & Motor & $\begin{array}{c}\text { Tegangan } \\
\text { (Volt) }\end{array}$ & $\begin{array}{c}\text { Putaran } \\
\text { Motor }\end{array}$ & $\begin{array}{c}\text { Waktu Rata- rata } \\
\text { (Detik) }\end{array}$ & $\begin{array}{c}\text { Kecepatan } \\
\text { rad/detik }\end{array}$ \\
\hline \multirow{2}{*}{1} & Kanan & 12,0 & 10 & 5,85 & 10,73 \\
\cline { 2 - 6 } & Kiri & 12,0 & 10 & 5,84 & 10,75 \\
\hline \multirow{2}{*}{2} & Kanan & 9,0 & 10 & 10,12 & 6,20 \\
\cline { 2 - 6 } & Kiri & 9,0 & 10 & 10,13 & 6,20 \\
\hline \multirow{2}{*}{3} & Kanan & 6,0 & 10 & 18,7 & 3,47 \\
\cline { 2 - 6 } & Kiri & 6,0 & 10 & 18,7 & 3,47 \\
\hline
\end{tabular}

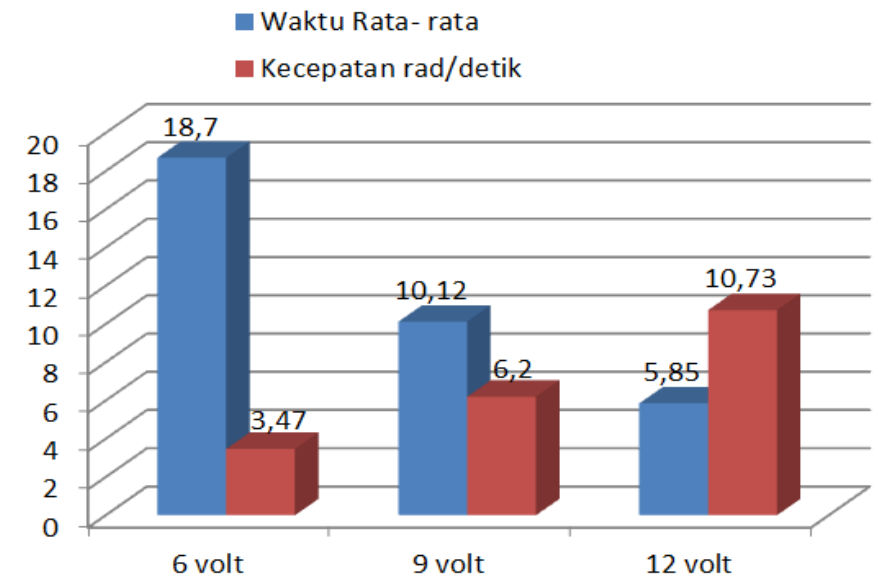

Gambar 2. Pengujian waktu dan kecepatan rata-rata Motor DC arah kanan

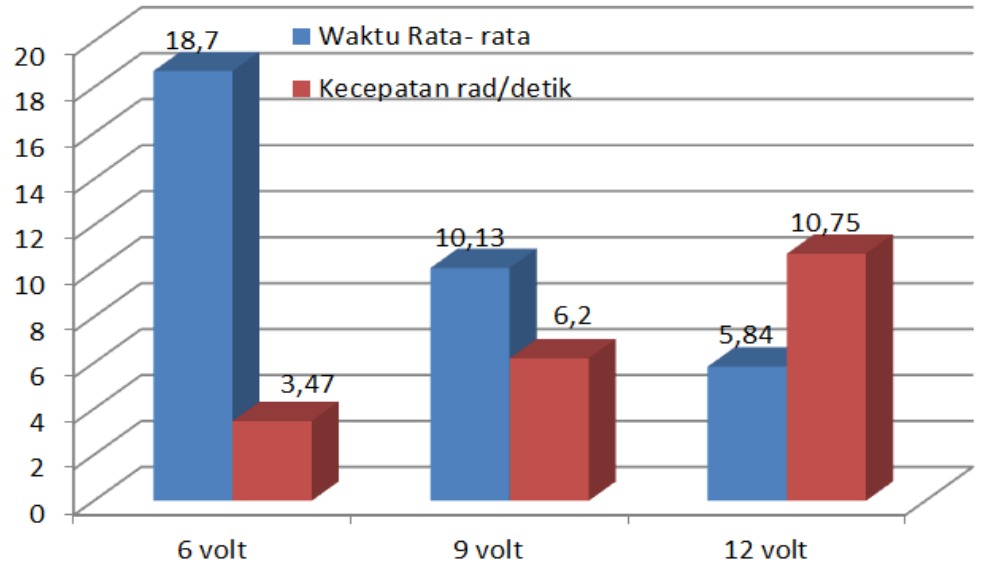

Gambar 3. Pengujian waktu dan kecepatan rata-rata Motor DC arah kiri

3. Pengujian Joystick

Pengujian control joysick ini dilakukan untuk mengetahui jangkauan kinerja pada control joystick seperti yang dilakukan pada jalan keramik, jalan beraspal jalan tanah dan jalan semen dengan jarak masing-masin 1 sampai 7 meter dalam setiap percobaan. 
4. Pengujian Mekanik

Pengujian ini bertujuan untuk mengetahui kekuatan konstruksi pemasangan motor pada kursi roda dan kekuatan motor menggerakan kursi roda dengan 3 percobaan diantaranya motor DC yang dipassang tanpa gear, motor DC yang terpasang menggunakan gear rasio kecil dan gear menggunakan rasio besar.

5. Pengujian Secara Keseluruhan

Pada pengujian ini seluruh rangkaian yang terpasang pada alat dioperasikan. Komponen yang diujikan dirangkai menjadi satu setelah itu dilakukan pengujian dengan menjalankan kursi roda.

Tabel 4..Pengujian Secara Keseluruhan

\begin{tabular}{|c|c|c|c|c|c|}
\hline No & $\begin{array}{l}\text { Perintah } \\
\text { Joystick }\end{array}$ & $\begin{array}{c}\text { Jarak } \\
\text { (meter) }\end{array}$ & $\begin{array}{c}\text { Massa beban } \\
\text { (detik) }\end{array}$ & $\begin{array}{l}\text { Waktu } \\
\text { (detik) }\end{array}$ & $\begin{array}{c}\text { Kecepatan } \\
\text { m/detik }\end{array}$ \\
\hline \multirow{4}{*}{1} & \multirow{4}{*}{ Maju } & & 0 & 9,13 & 5 \\
\hline & & & 15 & 14,89 & 0,3 \\
\hline & & & 25 & 18,02 & 0,2 \\
\hline & & 5 & 35 & 18,91 & 0,14 \\
\hline \multirow{4}{*}{2} & \multirow{4}{*}{ Mundur } & & 0 & 9,13 & 5 \\
\hline & & & 15 & 14,89 & 0,3 \\
\hline & & & 25 & 18,02 & 0,2 \\
\hline & & 5 & 35 & 18,91 & 0,14 \\
\hline \multirow{4}{*}{3} & \multirow{4}{*}{ Kanan } & \multirow{4}{*}{$\begin{array}{c}1 \\
\text { putaran }\end{array}$} & 0 & 3,12 & 2,01 \\
\hline & & & 15 & 3,64 & 1,72 \\
\hline & & & 25 & 4,87 & 1,28 \\
\hline & & & 30 & 5,23 & 1,20 \\
\hline \multirow{4}{*}{12} & \multirow{4}{*}{ Kiri } & & 0 & 3,12 & 2,01 \\
\hline & & & 15 & 4,66 & 1,33 \\
\hline & & 1 & 25 & 4,97 & 1,89 \\
\hline & & Putaran & 35 & 5,23 & 1,20 \\
\hline
\end{tabular}

Dari penelitian yang telah dilakukan maka dihasilkan bentuk fisik rancang bangun kursi roda elektrik untuk disabilitas berbasis mikrokontroler ATmega328 dapat dilihat pada gambar dibawah dan sfesifikasi dari kursi roda yang dihasilkan bisa dilhat pada tabel 


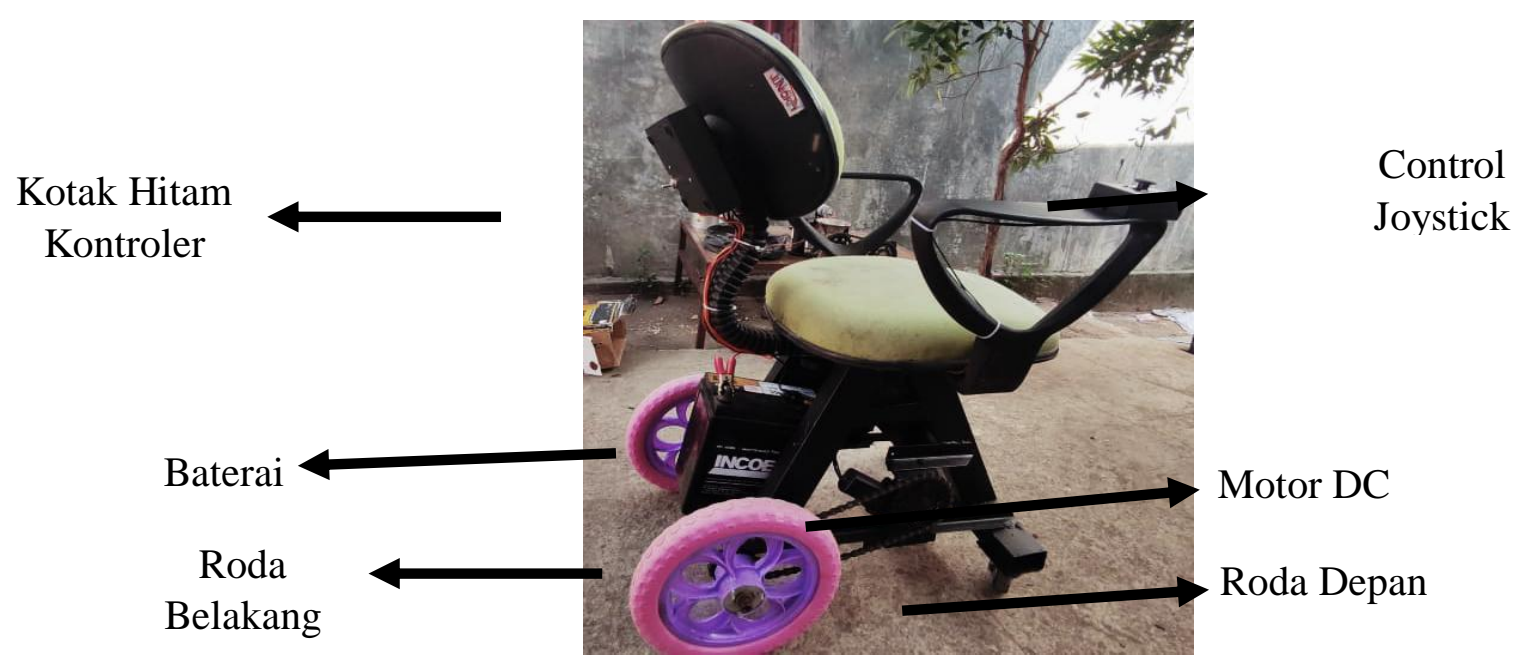

Gambar 1. Hasil Rancang Bangun Kursi Roda

Sfesifikasi dari Rancang Bangun Kursi Roda Elektrik untuk Dsabilitas Berbasis Mikrokontroler ATmega328 yang dihasilkan bisa dilhat pada tabel di bawah berikut.

Tabel 5 .Dimensi Dasar Rancang Bangun Kursi Roda

\begin{tabular}{llc}
\hline No & \multicolumn{1}{c}{ Uraian/Deskripsi } & Dimensi (mm) \\
\hline 1 & Panjang maksimum & 5700 \\
\hline 2 & Lebar & 6000 \\
\hline 3 & Tinggi total & 8400 \\
\hline 4 & Tinggi kursi & 4600 \\
\hline 5 & Lebar tempat duduk & 4200 \\
\hline 6 & Tinggi tempat duduk dari tanah & 5400 \\
\hline 7 & Tinggi sandaran tangan dari tempat duduk & 1700 \\
\hline 8 & Panjang tempat duduk & 4200 \\
\hline 9 & Tinggi sandaran & 2500 \\
\hline
\end{tabular}

Berdasarkan hasil pengamatan dan pengujian beberapa rangkaian dan komponen pada rancang bangun tugas akhir ini dapat disimpulkan, bahwa seluruh rangkaian dapat bekerja dengan baik dan sesuai dengan fungsi dari masing-masing komponen.

Catu daya yang digunakan pada alat ini adalah baterai MF (maintenance Free) yang memiliki tegangan sebesar $12 \mathrm{~V}$ dengan kapasitas baterai 32Ah. Pada saat baterai full tegangan keluaran yang di hasilkan bisa mencapai 13V. tegangan output dari baterai, digunakan sebagai sumber daya dari kontroler dan motor DC yang ada pada alat. Namun kapasitas daya pada baterai ini tidak bisa bertahan lama, hanya membutuhkan rentan waktu 30 menit saja.

Pada bagian sistem elektroniknya digunakan kontroler Arduino uno, modul draiver BTS, dan control joystick membutuhkan tegangan sebesar $5 \mathrm{~V}$ sehingga perlu rangkaian penurun tegangan dari $12 \mathrm{~V}$ menjadi $5 \mathrm{~V}$. Hasil yang diperoleh dari pengukuran tegangan mengalami penurunan tegangan yang stabil.

Pada rancang bangun kursi roda elektrik tersebut digunakan penggerak berupa Motor DC jenis power windows yang ukrannya sangat kecil, sehingga tidak mampu membawa 
beban terlalu berat. Untuk menghasilkan putaran yang kuat supaya mampu membawa beban yang besar maka harus digunakan motor DC yang lebih besar. Hal ini sesuai dengan yang telah dijabarkan oleh tim Suku Cadang Motor (2016) menyatakan bahwasanya motor listrik merupakan alat yang merubah energi listrik menjadi energi mekanik putar yang beroperasi melalui interaksi medan magnet dan konduktor pembawa arus untuk menghasilkan kekuatan.

Motor DC yang digunakan berjumlah dua dengan posisi yang berbed. Pengukuran tegangan dilakukan pada bagian output kontroler dan input motor DC. Hasil pengujian dapat disimpulkan bahwa motor DC dapat berputar dengan baik dengan tegangan input tidak kurang dari $6 \mathrm{v}$.

Adapun hasil pengujian mekanik penggerak kursi roda dari beberapa percobaan dengan menggunakan motor dan konstruksi pemasangan yang berbeda-beda diperoleh data seperti halnya pengujian pertama dengan menggunakan motor DC tanpa gearbox. Hasil dari mekanisme pada percoban pertama pada saat posisi dijakstand dapat berputar secara baik dan lancar tanpa hambatan, ketika kursi roda diturunkan dan diletakan kursi roda tidak dapat berjalan.

Pengujian kedua dilakukan penggantian dari menggunakan roda kecil digantikan dengan menggunakan rantai. Hasil ujicoba dari mekanisme kedua ini, saat kursi roda dijakstand kursi roda dapat berputar dengan baik tanpa ada hambatan. Ketika kursi roda diturunkan dan dicoba tanpa beban kursi roda dapat berjalan dengan baik dan cukup kencang akantetapi tarikan awalnya sangat berat

Pengujian ke tiga hampir sama dengan pengujian yang kedua hanya dilakukan penggantian pada gear yang ada pada roda kursi roda. Gear yang digunakan ukurannya lebih besar dari pada sebelumnya dengan menggunakan gear oneway gultrab, saat kursi roda dijakstand kursi roda dapat berputar dengan baik tanpa ada hambatan. Ketika kursi roda diturunkan dan dicoba tanpa beban kursi roda dapat berjalan dengan baik. Begitu juga ketika di berikan beban, kursi roda dapat berjalan dengan baik.

Maka dari hasil pengujian keseluruhan didapatkan bahwa alat sudah bekerja sesuai dengan yang diharapkan. Hasil pengujian keseluruhan kursi roda dapat membawa beban maksimal tidak lebih dari $35 \mathrm{~kg}$ dengan berat kursi $15 \mathrm{~kg}$ dan berat aki 10 sehingga berat keseluruhannya adalah $60 \mathrm{~kg}$.

\section{KESIMPULAN}

Pembuatan kursi roda elektrik untuk disabilitas berbasis mikrokontroler atmega328 dengan control joystick yaitu merakit kursi menjadi kursi roda elektrik otomatis dengan menambahkan penggerak yaitu dua buah motor DC dan sebuah catu daya yaitu baterai aki

\section{SARAN}

Kepada pembaca maupun peneliti selanjutnya, diharapkan dapat mencoba menyempurnakan penelitian ini dikarenakan terdapat kekurangan seperti control yang blum bisa diatur kecepatannya dan alat yang digunakan terlalu, oleh karena itu diharapkan untuk penelti selanjutnya bisa mengunakan draiver motor yang dapat sesuai dengan spesifikasi motor DC supaya kecepatan putaran motor dapat diatur dan menggunakan motor DC dengan arus yang lebih kecil dan torsi yang lebih besar. 


\section{DAFTAR PUSTAKA}

Ade (2016). Mikrokontroller Arduino UNO. Diambil pada 12 Februari 2021 pada https://datasheet.octopart.com/A000066-Arduino-datasheet-38879526.pdf

Dinata, Ugan. (2020). Cara Kerja Joystick. Diambil pada 26 Februari 2021 pada Rancangan Kurap Semeton.

Hinaoli, S. (2017). Baterai NP. Diambil pada 15 Februari 2021 pada Modul Astra Toyota.

Jatmika Yusep Nur. (2011). Cara Mudah Merakit Robot Untuk Pemula (hlm:35;36). FlashBooks. Yogkarta.

Nurcahyo Sidik. (2012). Aplikasi Dan Teknik Pemrograman Mikrokontroler AVR Atmel (hlm:4-8). C.VANDI OFFSET. Yogkarta.

Rajawali Putra, U. (2020). Jenis-jenis kabel listrik. Diambil pada 12 Februari 2021 pada https://rajawaliutama.co.id/10-jenis kabel-listrik.

Sukucadangmotor (2016). Dynamo stater honda grand. Diambil pada 12 Februari 2021 pada https://www.serayamotor.com/diskusi/viewtopic.php?t=16449

Utomo, Budiman Setyo. (2018). "Kursi Roda Terkendali Otomatis Speech Recognition Dengan Bluetooth Berbasis Android”. Diambil pada 5 Februari 2021 pada Tugas Akhir. Fakultas Teknik Universitas Negri Yogyakarta. Yogyakarta.

Prasetiyo, Febriono Aji. (2019). "Kendali Kemudi Tambahan Untuk Mobilitas Kursi Roda Berbasis Arduino Mega 2560”. Skripsi (Hlm: 7-9). Di Anmbil Pada 5 Februari Pada Program Sarjana Fakultas Tehnik Sain Dan Tehnologi Universitas Sanata Drama Yogyakarta. Yogyakarta 